\title{
Establishment of CXCR4-small interfering RNA retrovirus vector driven by human prostate-specific antigen promoter and its biological effects on prostate cancer in vitro and in vivo
}

\author{
Yue-Feng Du $\cdot$ Ying Shi $\cdot$ Yi-Fei Xing $\cdot$ Fu-Qing Zeng
}

Published online: 1 October 2008

(C) Springer-Verlag 2008

\section{Erratum to: J Cancer Res Clin Oncol DOI 10.1007/s00432-008-0394-2}

The wrong corresponding author was indicated.

The list of authors should read:

Yue-Feng Du · Ying Shi $\cdot$ Yi-Fei Xing $(\varangle)$, Fu-Qing Zeng

Department of Urology, Union Hospital, Tongji Medical

College, Huazhong University of Science and Technology,

Wuhan 430022, China

e-mail: yfxing@yahoo.com

The following acknowledgements was omitted:

This work was supported by the National Natural Science Foundation of China (Grant 30300348 to Yi-Fei Xing).

The current address of Yue-Feng Du was not included:

Department of Urology, The First Affiliated Hospital of Xi' an Jiaotong University, Xi' an, Shanxi 710061, China

The online version of the original article can be found under doi:10.1007/s00432-008-0394-2.

Y.-F. Du · Y. Shi · Y.-F. Xing $(\varangle) \cdot$ F.-Q. Zeng

Department of Urology, Union Hospital, Tongji Medical College,

Huazhong University of Science and Technology,

Wuhan 430022, China

e-mail: yfxing@yahoo.com

Present Address:

Y.-F. Du

Department of Urology,

The First Affiliated Hospital of Xi' an Jiaotong University,

Xi'an, Shanxi 710061, China 